\title{
Macrofollicular variant of papillary thyroid carcinoma with metastasis to femur
}

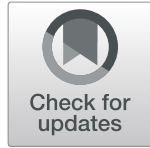

\author{
Fernando Candanedo-Gonzalez ${ }^{*}$ D, Diana Rodriguez-Orihuela and Julian Arista-Nasr
}

\begin{abstract}
Background: Macrofollicular variant of papillary thyroid carcinoma (MFV-PTC) is a rare subtype with histological features and an indolent clinical course that can be confused with nodular goiter or follicular adenoma. However, on rare occasions it may show more aggressive biological behavior. Only two cases of MFV-PTC with bone metastases have been reported previously. We describe the clinical-pathological characteristics of a man with MFVPTC that developed femur metastasis. This the first case of MFV-PTC with femur metastases diagnosed histologically by means of an image-guided core needle biopsy in English literature.

Case presentation: A 33-year-old man presented two years earlier with swelling in the right neck associated with weight loss and pain in the left knee. Neck ultrasonography showed hyperechogenic and hypogenic nodular images in the thyroid's right lobe. A fine needle aspiration biopsy specimen was initially interpreted as nodular hyperplasia. A CT showed a large tumor involving right thyroid lobe with trachea and vascular structures displaced to the right, and a total thyroidectomy was performed. Subsequently, a MRI of the knee confirmed the presence of a destructive tumor in the femur. A guided core-needle biopsy of the knee tumor showed the presence of metastatic MFV-PTC. Re-assessment of the histology from thyroidectomy was also consistent with MFV-PTC. A whole-body ${ }^{18}$ F-FDG PET/CT showed presence of lesions in the left anterior costal arch, metaphysis of the left femur and in the sternum handle. Therefore, he received $200 \mathrm{mCi}$ radioactive iodine, and $40 \mathrm{~Gy}$ of radiotherapy to left costal arches and knee, which decreased his symptoms. Currently, after 10 months of follow-up, the patient is alive with bone tumor activity.

Conclusions: Our case supports the view that, on rare ocassions, MFV-PTC may show a more aggressive biological behavior than expected. The synchronous or asynchronous presence of one or more bone lesions, should raise the suspicion of metastasis. Given the suspicion, it is necessary to take a biopsy to confirm histologically. Only a careful analysis of the architectural and cytological characteristics of goiter or hyperplastic nodules will allow to recognize this rare variety of carcinoma.
\end{abstract}

Keywords: Thyroid carcinoma, Macrofollicular variant of papillary thyroid carcinoma, Bone metastases, Femur

\footnotetext{
* Correspondence: fa_candanedo@yahoo.com.mx

Department of pathology, Instituto Nacional de Ciencias Medicas y Nutricion

Salvador Zubiran, Av. Vasco de Quiroga No. 15. Col: Belisario Dominguez

Seccion XVI, Delegacion: Tlalpan, 14080 Ciudad de Mexico, Mexico
}

(c) The Author(s). 2020 Open Access This article is licensed under a Creative Commons Attribution 4.0 International License, which permits use, sharing, adaptation, distribution and reproduction in any medium or format, as long as you give appropriate credit to the original author(s) and the source, provide a link to the Creative Commons licence, and indicate if changes were made. The images or other third party material in this article are included in the article's Creative Commons licence, unless indicated otherwise in a credit line to the material. If material is not included in the article's Creative Commons licence and your intended use is not permitted by statutory regulation or exceeds the permitted use, you will need to obtain permission directly from the copyright holder. To view a copy of this licence, visit http://creativecommons.org/licenses/by/4.0/. The Creative Commons Public Domain Dedication waiver (http://creativecommons.org/publicdomain/zero/1.0/) applies to the data made available in this article, unless otherwise stated in a credit line to the data. 


\section{Background}

Macrofollicular variant of papillary thyroid carcinoma (MFV-PTC) was described in 1991 by Albores-Saavedra et al [1]. It is a rare variant of papillary carcinoma with a frequency of $2.6 \%$ [2], characterized by highly dilated thyroid follicles in more than $50 \%$ of the neoplasm and resembles thyroid adenoma or nodular colloid goiter. Most have a good prognosis and are generally encapsulated. In the original series of 17 patients, two presented with lymph node metastases and later, other authors found similar cases [3-5]. In 2009, Cardenas et al [6] reported two patients who presented with bone metastases. We describe the clinical pathological characteristics of a 33-year-old man with MFV-PTC that was initially misdiagnosed as a benign goiter following a fine-needle aspiration (FNA) biopsy of the thyroid, with synchronous metastases to the left femur and ribs. This is the first report of MFV-PTC with femur metastases histologically documented by means of an image-guided core needle biopsy in English literature.

\section{Case presentation}

A 33-year-old mestizo man, who in 2017, noticed a swelling in the right neck associated with weight loss and pain in the left knee; hence he consulted a doctor outside of our institution. On physical examination, he had an asymmetrical neck, with trachea deviated to the left, and a hard mass, in the thyroid gland, not fixed to deep planes. No adenomegalies were palpable. A year later he presented dysphagia to solids, asthenia, adinamia, dyspnea and snoring. Thyroid ultrasound showed hyperechogenic and hypoechogenic nodular lesions with necrotic center and microcalcifications in the right lobe. The nodules measured between 10 and $18 \mathrm{~mm}$ in diameter with increased perfusion around the nodular lesions. The right lobe measured $95 \times 52 \times 67 \mathrm{~mm}$ and the left lobe measured 39x16x17 mm. Angio-Doppler showed diffuse isoechoic feature and was classified as TI-RADS 4A (Thyroid Imaging and Reporting System). No locoregional lymph node growth was observed. A FNA biopsy of the thyroid gland was initially interpreted as nodular hyperplasia (Bethesda 2). Therefore, he was referred to our institution for further management. Laboratory investigations showed serum thyroglobulin $1359.67 \mathrm{ng} / \mathrm{mL}$ (0-36.8), thyroid stimulating hormone (TSH) $3.57 \mathrm{mlU} /$ $\mathrm{L}$ (0.3-5), total tetraiodothyronine (T4T) $8.45 \mu \mathrm{g} / \mathrm{dL}$ (5.91-12.56), free tetraiodothyronine (FT4) $0.74 \mathrm{ng} / \mathrm{dL}$ (0.63-1.34), total triiodothyronine (T3T) $1.91 \mathrm{ng} / \mathrm{mL}$ (0.64-1.81), free triiodothyronine (FT3) $4.21 \mathrm{pg} / \mathrm{mL}$ (2.5-3.9), T3 resin uptake $42.8 \%$ (24-37), anti-thyroid peroxidase antibodies $<1: 1200 \mathrm{IU} / \mathrm{mL}$ (negative). In April 2019, a computed tomography (CT) of the neck was performed that confirmed the presence of a tumor involving the right thyroid lobe with central necrosis that displaced the upper third of the trachea and vascular structures on the right side of the neck with high level of peripheral reinforcement in the sequence with contrast medium (Fig. 1a). In August 2019, total thyroidectomy was performed. On the other hand, the examination of the left knee showed a swelling in the medial side, which was painful to mobilize and had a hard consistency. A magnetic resonance imaging (MRI) of the knee confirmed the presence of a destructive tumor in the diaphysis and epiphysis of the femur, which measured $82 \times 54 \times 52 \mathrm{~mm}$, involving the articular medial intercondylar component and the posterior cruciate ligament (Fig. $1 \mathrm{~b}$ and $\mathrm{c}$ ). An imaging guided core-needle biopsy of the knee tumor showed a presence of metastatic thyroid carcinoma. In October 2019, a whole-body ${ }^{18} \mathrm{~F}$ fluorodeoxyglucose positron emission tomography and computed tomography $\left({ }^{18} \mathrm{~F}-\mathrm{FDG} \mathrm{PET} / \mathrm{CT}\right)$ was performed, which showed the presence of a $5.3 \times 4.1 \mathrm{~cm} \mathrm{le-}$ sions in the left anterior costal arch with 4.6 SubMax. The scan also showed a $6.9 \times 4.7 \mathrm{~cm}$ lesion with SubMax of 7.1 in the left femur and a mixed lesion in the sternum handle, with SubMax of 2.5. Therefore, in November, 2019 he received a therapeutic dose of radioactive iodine (RAI) of $200 \mathrm{mCi}$ and zoledronic acid, as well as 40 Gy (divided in 10 fractions) of local external radiotherapy to the left costal arches and the knee, which decreased his symptoms. Currently, after 10 months of follow-up, the patient is alive with bone tumor activity.

\section{Materials and methods}

The tissue was fixed in 10\% buffered formaldehyde and paraffin embedded. For immunohistochemistry (IHC) analysis, $5 \mu \mathrm{m}$ sections of a representative block were obtained. The following antibodies were used: Thyroid Transcription Factor-1 (TTF-1) and thyroglobulin. IHC analyses were performed on an automated immunostainer (Ventana, Biotek System, Tucson, Arizona) with appropriate positive and negative control run concurrently. Briefly, paraffin sections were mounted on charged glass slides, air-dried over-night, and then deparaffinized. To enhance the immunostaining, a heat-induced epitoperetrieval procedure was performed. After incubation with blocking serum, sections were incubated with primary antibodies, followed by a biotinylated polyvalent secondary antibody solution. Sections were then incubated with horseradish peroxidase conjugated avidinbiotin complex, followed by 3, 3-diaminobenzidine and hydrogen peroxidase.

\section{Pathologic findings}

Macroscopically, the right thyroid lobe weighed $130 \mathrm{~g}$ and measured $8.6 \times 7.5 \mathrm{~cm}$. At the cut, multiple nodules of variable size were identified with a central zone with 

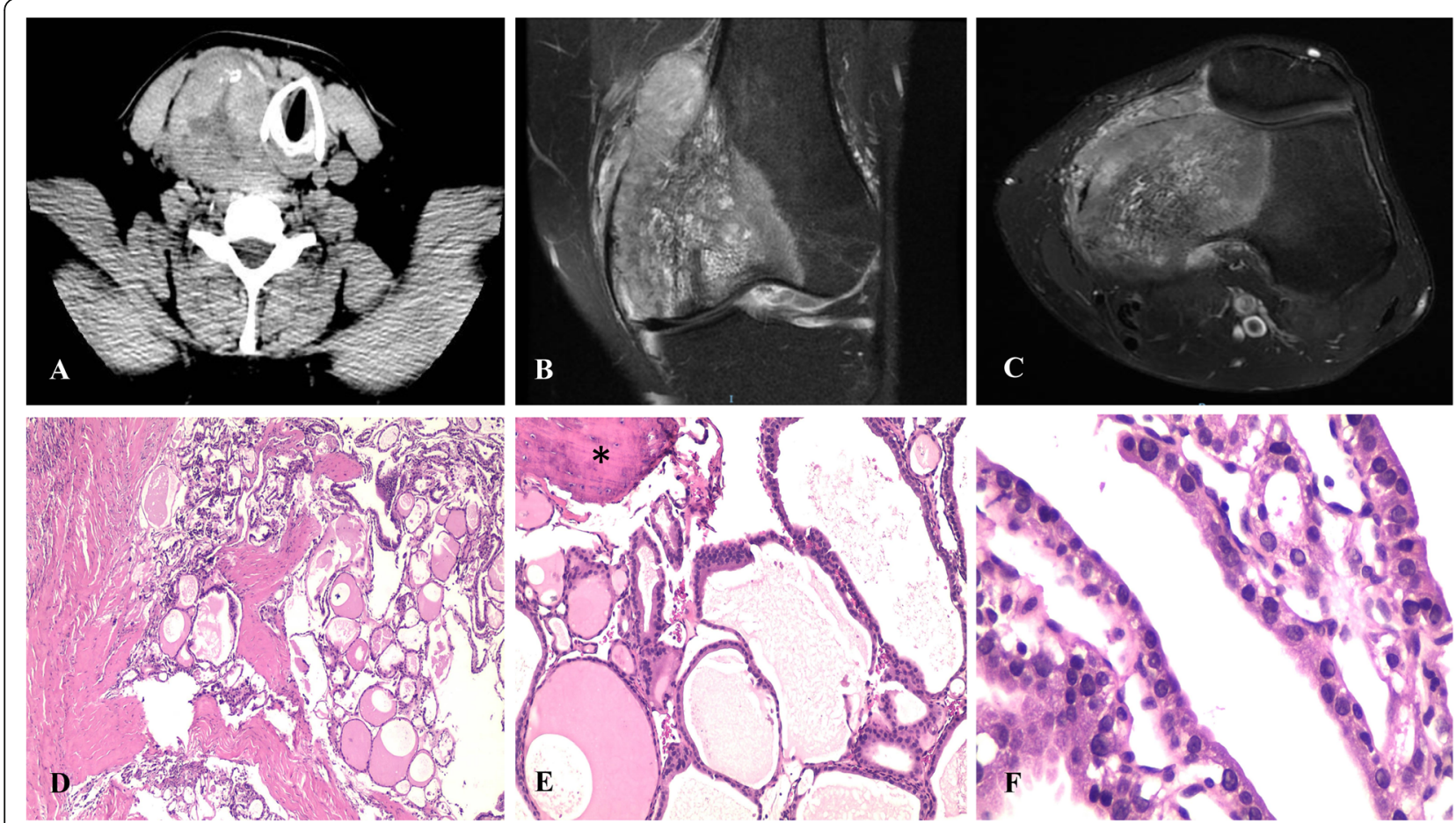

Fig. 1 Metastatic macrofollicular thyroid carcinoma to femur. a CT showed the presence of a tumor involving right thyroid lobe with central necrosis that displaced the upper third of the trachea and the vascular structures on the right side of the neck; $\mathbf{b}$ and $\mathbf{c}$ MRI showed a destructive neoplasm in the diaphysis and epiphysis of the femur; $\mathbf{d}$ The neoplasm showed large follicles in more than 50\% of the neoplastic follicles; $\mathbf{e}$ Immersed in the metastasis of macrofollicular variant papillary thryroid carcinoma, a bone spicule was observed (*); $\mathbf{f}$ Follicles were lined by atypical nuclei and some showed pseudoinclusions

multiple calcifications. The left thyroid lobe and isthmus weighed $8.5 \mathrm{~g}$, and measured $4.5 \times 2.0 \mathrm{~cm}$.

Microscopically, both the right thyroid lobe and the tumor in the femur showed a neoplasm composed mainly of macrofollicles with abundant colloids, and a complete absence of well-formed papillary structures (Fig. 1d). The nuclei of the neoplasic cells showed ground-glass opacity with nuclear overlapping (Fig. 1e and f). No mitosis or necrosis were observed. On IHC, the neoplasm cells were positive for thyroglobulin and TTF-1 diffusely.

\section{Discussion}

Papillary thyroid carcinoma (PTC) is the most common malignant neoplasm of the thyroid gland. It represents $80 \%$ of all thyroid malignancies [7]. PTC has a morphologically broad spectrum. The MFV-PTC is a rare subtype, which was defined for the first time by AlboresSaavedra et al., in 1991 [1]. In the original description it was established that the follicles of MFV-PTC occupied over $50 \%$ of the cross-sectional areas of the tumors. The macrofollicles were lined either by cells with enlarge ground-glass clear nuclei, and nuclear grooves or cuboidal cells with hyperchromatic nuclei [1]. All patients were females ranging in age from 15 to 69 years (mean,
35.4 years). MFV-PTC is a well-differentiated neoplasms usually with an indolent clinical course. Despite high survival rates, some patients may present with local recurrence, and metastasis and this may require more aggressive treatment.

The most frequent sites of metastasis in PTC are locoregional lymph nodes, especially cervical and mediastinal nodes. On the other hand, the most common sites of distant metastases are lungs and bones. Bone metastases most often occur in the scapula, sternum and ilium. However, bone metastases are most often caused by follicular thyroid carcinoma, while only 1.4 to $7 \%$ of PTCs produce bone metastases [8-10]. There are retrospective studies that have suggested that the MFV-PTC has a better prognosis as compared to the classical form, with its lower rate of lymph node metastases [11]. Despite being a low grade malignant neoplasm, cases with nodal and pulmonary metastases from MFV-PTC have been reported. However, there are only two cases of particularly aggressive MFV-PTC with extensive bone dissemination, previously reported by Cardenas et al [6]. The first case corresponded to a 59-year-old woman with a metastasis in the occipital bone, ribs, thoracic, lumbar spine and pelvic bones. Thyroidectomy showed a $3 \mathrm{~cm}$ diameter MFV-PTC. The second case was an 81- 
Table 1 Clinical characteristics of all patients informed with MFV-PTC metastatic to bone

\begin{tabular}{|c|c|c|c|c|c|c|}
\hline Author (Ref.) & No. of cases & Age/Gender & $\begin{array}{l}\text { Average tumor } \\
\text { size }(\mathrm{cm})\end{array}$ & Bones involved & Treatment & Outcome \\
\hline \multirow[t]{2}{*}{ Cardenas et al. [6] } & 1 & $59 / \mathrm{W}$ & 3.0 & $\begin{array}{l}\text { Ribs, vertebrae T12, L5 } \\
\text { sacrum, righ ischium, } \\
\text { and left femoral neck. }\end{array}$ & RAl $206 \mathrm{mCi}$ of ${ }^{131}$ I & $\begin{array}{l}\text { Alive with minimal } \\
\text { residual disease. }\end{array}$ \\
\hline & 2 & $81 / \mathrm{M}$ & 12.0 & Scapular right. & RAl $206 \mathrm{mCi}$ of ${ }^{131}$ I & $\begin{array}{l}\text { Died } 6 \text { years later with } \\
\text { disease. }\end{array}$ \\
\hline $\begin{array}{l}\text { Candanedo et al. } \\
\text { (Present case) [9] }\end{array}$ & 1 & $33 / \mathrm{M}$ & 8.2 & $\begin{array}{l}\text { Femur diaphysis, epiphysis } \\
\text { and sternum handle }\end{array}$ & $\begin{array}{l}\text { RAl } 200 \text { mCi of }{ }^{131} \text { I } \\
\text { and radiotherapy } \\
40 \text { Gy in } 10 \text { fractions }\end{array}$ & $\begin{array}{l}\text { Alive } 10 \text { months with } \\
\text { residual disease }\end{array}$ \\
\hline
\end{tabular}

Ref References; W Women; M Man; RAl Radioactive lodine; Gy Gray

year-old man with a thyroid nodule that was originally interpreted as a nodular colloid goiter. Three years later, he developed a neoplastic mass in his right shoulder that was confirmed to be MFV-PTC. Following the review of the thyroid nodule, the lesion was reclassified as MFVPTC. Subsequently, other bone and lung lesions were documented. The evolution was unfavorable and he died. We report the third case of bone metastasis from MFV-PTC. Like the previously reported case [6], our case was initially misdiagnosed as colloid goiter following both FNA biopsy, as well as thyroidectomy. The peculiarity of our case is that the patient presented a synchronous femoral tumor, which was not previously investigated. It was only after an MRI of the left knee with femur biopsy performed in our institution, that confirmed the presence of bone metastases from a thyroid carcinoma. Histologically, the metastasis was very similar to that observed in the thyroid gland, and which in retrospect was also consistent with a MFV-PTC. Our case is the first in English literature to show femur metastases diagnosed histologically by means of and an image guided core-needle biopsy. Table 1 summarizes some characteristics of the published cases of MFV-PTC metastatic to bone.

MFV-PTC represents a source of diagnostic error because it manifest clinically as a thyroid nodule, it can be easily confused with goiter, macrofollicular adenoma, folicular neoplasia or hyperplastic nodule [11], as in our case. Since the 80's, FNA has emerged as a good diagnostic tool for investigation of thyroid nodules, due to its high diagnostic accuracy and low complication rate [12]. However, FNA biopsy does not seem to be the best investigation to diagnose MFV-PTC. Because, most cases of MFV-PTC are moderately to highly cellular with the presence of microfollicles and macrophages, and the nuclear characteristics of PTC are absent or focal in all cases [13-15]. On the other hand, the image guided core-needle biopsy is a useful method that provides an accurate diagnosis. It allows to determine a possible primary site of origin, using small simples, when we are faced with a metastasis as in our case.

\section{Conclusion}

We have reported the case of a man with MFV-PTC that developed metastasis to the femoral bone. This case confirms the view that MFV-PTC can ocassionally be very aggressive. Only a careful analysis of the architectural and cytological characteristics of goiter or hyperplastic nodules will allow to recognize this rare variety of carcinoma.

\section{Abbreviations \\ CT: Computed tomography; ${ }^{18}$ F-FDG PET/CT: ${ }^{18}$ F-fluorodeoxyglucose positron emission tomography and computed tomography; FNA: Fine- needle aspiration biopsy; FT3: Free triiodothyronine; FT4: Free tetraiodothyronine; Gy: Gray (a unit derived the dose of ionizing radiation in the International System of Units); IHC: Immunohistochemistry; MFV- PTC: Macrofollicular variant of papillary thyroid carcinoma; MRI: Magnetic resonance imaging; PTC: Papillary thyroid carcinoma; RAI: Radioactive iodine; TI-RADS: Thyroid imaging reporting and data system; TSH: Thyroid stimulating hormone; TTF-1: Thyroid transcription factor-1; T3T: Total triiodothyronine; T4T: Total tetraiodothyronine}

\section{Acknowledgments}

We wish to thank Ricardo Aguilar for assistance in immunohistochemistry.

\section{Authors' contributions}

FCG, and ANJ made substantial contributions to conception and design of the study; FCG, ROD and ANJ analyzed the data; FCG collected the sample; FCG, and ROD made contributions to adquisition of clinica data; ROD analyzed and described the characteristics of the tumor on $C T$ and MRI; FCG, ROD and ANJ evaluated the histological findings and the results of the immunohistochemistry; FCG, ROD and ANJ draft the paper. All authors have given approval the final version of manuscript to be published.

\section{Funding}

No funding has been gained by the authors for this research.

\section{Availability of data and materials}

Not applicable. Data sharing is not applicable for this article because no datasets were generated or analyzed during the current study.

\section{Ethics approval and consent to participate}

Not applicable for case report.

\section{Consent for publication}

Written informed consent was obtained from the patient for publication of this case report and any accompanying images. A copy of the consent is available for the Editor-in Chief of this Journal to review.

\section{Competing interests}

The authors declare that they have no competing interest. 
Received: 13 December 2019 Accepted: 3 June 2020

Published online: 13 June 2020

\section{References}

1. Albores-Saavedra J, Gould E, Vardaman C, Vuitch F. The macrofollicular variant of papillary thyroid carcinoma: a study of 17 cases. Hum Pathol. 1991;22;1195-1205. https://doi.org/10.1016/0046-8177(91)90101-t.

2. Gamboa-Dominguez A, Vieitez-Martinez I, Barredo-Prieto BA, Richaud-Patin Y, Herrera ME, Angeles-Angeles A. Macrofollicular variant of papillary thyroid carcinoma: a case and control analysis. Endocr Pathol. 1996;7(4):303-8. https://doi.org. https://doi.org/10.1007/bf02739837.

3. Lee YS, Kim SY, Hong SW, Kim SM, Kim BW, Chang HS, et al. Ultrasonographic features and clinicopathologic characteristics of macrofollicular variant papillary thyroid carcinoma. Medicine (Baltimore) 2018;97(9): e8105. https://doi.org/10.1097/MD.0000000000008105.

4. Min-kyung Y, Ja Seong B, Woo Jin O, Gyeong Sin P, Chan Kwon J. Macrofollicular variant of papillary thyroid carcinoma with extensive lymph node metastases. Endocr Pathol 2014;25:265-272. https://doi.org/10.1007/ s12022-014-9306-y.

5. Nakamura T, Moriyama S, Nariya S, Sano K, Shirota H, Kato R. Macrofollicular variant of papillary thyroid carcinoma. Pathol Int 1998;48:467-470. https:// doi.org/10.4103/0256-4947.87104.

6. Cardenas MG, Kini S, Wisgerhof M. Two patients with highly aggressive macrofollicular variant of papillary thyroid carcinoma. Thyroid 2009;19:413416. https://doi.org/10.1089/thy.2008.0178.

7. LiVolsi VA. Papillary thyroid carcinoma: an update. Mod Pathol 2011;24 Suppl 2:S1-S9. https://doi.org/10.1038/modpathol.2010.129.

8. Proye CA, Dromer DH, Carnaille BM, Gontier AJ, Goropoulos A, Carpentier P, et al. Is it still worth while to treat bone metastases from differentiated thyroid carcinoma with radioactive iodine? World J Surg 1992;16(4):640-645 https://doi.org/10.1007/bf02067343.

9. Candanedo-Gonzalez F, Romero Utrilla A, Osuna-Ramos JF, AlvaradoSanchez C, Camacho-Rebollar L, Mendez-Perez VJ, et al. Occult folicular thyroid carcinoma presenting as primary breast tumor with sternal and skull metastasis. Am J Cancer Case Reports. 2015;3:1-6.

10. Durante C, Haddy N, Baudin E, Leboulleux S, Hartl D, Travagli JP, et al. Longterm outcome of 444 patients with distant metastases from papillary and folicular thyroid carcinoma: benefits and limits of radioiodine therapy. J Clin Endocrinol Metab. 2006;91:2892-9. https://doi.org. https://doi.org/10.1210/jc. 2005-2838.

11. Yeo MK, Bae JS, Oh WJ, Park GS, Jung CK. Macrofollicular variant of papillary thyroid carcinoma with extensive lymph node metastases. Endocr Pathol. 2014;25(3):265-72. https:/doi.org. https://doi.org/10.1007/s12022-014-9306-y.

12. Silverman JF, West RL, Finley JL, Larkin EW, Park HK, Swanson MS, et al. Fineneedle aspiration versus large needle biopsy or cutting biopsy in evaluation of thyroid nodules. Diagn Cytopathol 1986;2:25-30. https://doi.org/10.1002/ dc.2840020107.

13. Lugli A, Terracciano LM, Oberholzer M, Bubendorf $L$, Tornillo $L$. Macrofollicular variant of papillary carcinoma of the thyroid: a histologic, cytologic, and immunohistochemical study of 3 cases and review of the literature. Arch Pathol Lab Med 2004;128(1):54-58. https://doi.org/10.1043/ 1543-2165(2004)128<54:MVOPCO>2.0.CO;2.

14. Hirokawa M, Shimizu M, Terayama K, Kanahara T, Sonoo H, Manabe T. Macrofollicular variant of papillary thyroid carcinoma. Report of a case with fine needle aspiration biopsy findings. Acta Cytol 1998;42:1441-1443. https://doi.org/10.4103/1742-6413.117352.

15. Chung D, Ghossein RA, Lin O. Macrofollicular variant of papillary carcinoma: a potential thyroid FNA pitfall. Diagn Cytopathol 2007;35(9):560-564. https:// doi.org/10.1002/dc.20702.

\section{Publisher's Note}

Springer Nature remains neutral with regard to jurisdictional claims in published maps and institutional affiliations.

Ready to submit your research? Choose BMC and benefit from:

- fast, convenient online submission

- thorough peer review by experienced researchers in your field

- rapid publication on acceptance

- support for research data, including large and complex data types

- gold Open Access which fosters wider collaboration and increased citations

- maximum visibility for your research: over $100 \mathrm{M}$ website views per year

At BMC, research is always in progress.

Learn more biomedcentral.com/submissions 